\title{
Analysis of oxide scale deformation and surface roughness characterisation in hot rolling of stainless steels
}

\section{Xiawei Cheng*}

Faculty of Engineering and Information Sciences, University of Wollongong,

Wollongong NSW 2522, Australia

Email: xc979@uowmail.edu.au

*Corresponding author

\section{Dongbin Wei}

School of Electrical, Mechanical and Mechatronic Systems,

University of Technology,

Sydney 15 Broadway, Ultimo,

NSW 2007, Australia

Email: dongbin.wei@uts.edu.au

\section{Zhengyi Jiang}

Faculty of Engineering and Information Sciences,

University of Wollongong,

Wollongong NSW 2522, Australia

Email: jiang@uow.edu.au

\section{Laizhu Jiang}

Baosteel Research Institute (R\&D Centre),

Baoshan Iron \& Steel Co., Ltd.,

Shanghai, 200431, China

Email: lzjiang@baosteel.com

\begin{abstract}
Stainless steels are iron-based alloys that contain a minimum of about $12 \% \mathrm{Cr}$. They have been classified by microstructure at room temperature. Two stainless steel grades 304 and 410L were studied in this paper. Hot rolling was performed on a Hille 100 experimental rolling mill under various reductions with consideration of the oxide scale thickness controlled by oxidation time. The experimental results show that the deformation behaviour of the oxide scale on the stainless steel 304 is sensitive to its thickness and exhibits higher resistance to be deformed. However, the reduction in thickness plays an important role in the uniformity of the oxide scale deformation for the stainless steel $410 \mathrm{~L}$. Friction coefficients were
\end{abstract}


calculated and compared. Simulations results show that the reduction in thickness and initial surface roughness play roles on final surface roughness. Steel substrate surface is rougher than that of the oxide scale at different reductions.

Keywords: stainless steel; deformation; friction; surface roughness; oxide scale.

Reference to this paper should be made as follows: Cheng, X., Wei, D., Jiang, Z. and Jiang, L. (2017) 'Analysis of oxide scale deformation and surface roughness characterisation in hot rolling of stainless steels', Int. J. Surface Science and Engineering, Vol. 11, No. 3, pp.241-261.

Biographical notes: Xiawei Cheng is an Associate Research Fellow in the School of Mechanical, Materials and Mechatronic Engineering, University of Wollongong. Her main research interests include tribology in material processing, surface engineering, oxidation of metals and corrosion engineering.

Dongbin Wei is a Senior Lecturer in School of Electrical, Mechanical and Mechatronic Systems, University of Technology, Sydney. His research interests include modelling of metal forming processes, tribology in metal forming, micro-metal forming and surface engineering.

Zhengyi Jiang is a Professor in the School of Mechanical, Materials and Mechatronic Engineering, University of Wollongong. His main research interests include modelling of metal forming processes, tribology in metal forming, micro-metal forming and defect control in metal forming process.

Laizhu Jiang is the Vice President in the Baosteel Research Institute (R\&D Center). He is one of the top experts in both microalloyed steels and stainless steels in Baosteel. His research interests include stainless steel processing and tribology in metal forming.

\section{Introduction}

The consumption of stainless steel across the world is on a steady growth due to its applications in the process industry, construction, consumer products, kitchen wares and so on (Baddoo, 2008; McGuire, 2008; Kaladhar et al., 2012; Vignal et al., 2014). In hot rolling, the stainless steel slabs are firstly placed in the reheating furnace to a high temperature. The oxidation of stainless steels is significantly affected by the alloying elements and atmosphere, and this means that its oxidation is more complex than that of carbon steels. The two major potential components of a stainless steel oxide scale are $\mathrm{M}_{2} \mathrm{O}_{3}$ rhombohedral phase and $\mathrm{M}_{3} \mathrm{O}_{4}$ spinel phase (Reichardt, 2001). Spinel crystallite oxides always exist in the hot working of stainless steels. For instance, the Fe-Cr spinel is located upon the steel substrate of ferrtic stainless steel SUS 430 (Cheng et al., 2015b); the $\mathrm{Mn}-\mathrm{Cr}$ spinel is on top of the $\mathrm{Cr}_{2} \mathrm{O}_{3}$ scale on ferritic stainless steel B445J1M (Cheng et al., 2015c). 
The deformation behaviour of the oxide scale on carbon steel can be characterised as brittle, mixed, or ductile, based on its integrity between $650^{\circ} \mathrm{C}$ and $1,050^{\circ} \mathrm{C}$ in hot rolling (Suárez et al., 2009). The oxide scale shows various deformation behaviours (Krzyzanowski et al., 2010; Krzyzanowski and Beynon, 2006; Utsunomiya et al., 2014). For instance, uniform deformation with matrix steel, cracking, fragmentation, and indentation to matrix steel. It is found that the oxide scale deformation behaviour strongly depends on the rolling temperature and the oxide scale thickness (Munther and Lenard, 1999). However, all the researches above were concerned about carbon steels on which iron oxides; especially $\mathrm{FeO}$ is the main constituent of the oxide scale in hot process. It was found that the composition of the oxide scale on stainless steel plays a significant role on its tribological effect in hot rolling. Thin, hard, and brittle oxide scale causes severe roll wear (Cheng et al., 2015c). Thinner Fe-Cr spinel is prone to be fragmented at a high reduction and displays improved ductility (Cheng et al., 2015a). Hidaka et al. (2006) concluded that plastic deformation by dislocation would occur to some extent in $\mathrm{Fe}_{3} \mathrm{O}_{4}$ and $\mathrm{FeCr}_{2} \mathrm{O}_{4}$ crystals, but they would be broken when under high rolling reduction. The deformation of oxide scale and the transformation of the surface roughness were investigated (Wei et al., 2009a, 2009b, 2011; Zhang et al., 2012). Oxide scale thickness decreases with an increase of rolling reduction (Sun et al., 2004a), and higher reduction and thinner oxide scale result in better surface.

The surface of an oxidised hot steel strip is reported to be rough (Sun et al., 2004a). The oxide scale may be depressed deeper into the strip surface and the hot metal is extruded outward to fill the void between the oxide scale cracks, thus, a rougher surface is generated (Jiang et al., 2006). Surface roughness is an important index of the quality of a rolled strip (Tieu et al., 2007; Jiang et al., 2008; Zhang et al., 2009). Researchers carried out hot rolling test of low carbon steel, and found that the surface roughness decreases remarkably in the case of thick primary oxide scale (Jiang et al., 2006; Sun et al., 2004a), however, the ability to decrease surface roughness by the deformation of thin secondary oxide scale is very limited. Chang et al. (2013) found that the rolling temperature is an important factor affecting the surface roughness $\mathrm{R}_{\mathrm{a}}$ of low carbon strip. When the amount of the outer brittle $\alpha-\mathrm{Fe}_{2} \mathrm{O}_{3}$ formed above $927^{\circ} \mathrm{C}$ increases, the roughness of the product will increase.

This paper investigates the deformation of oxide scale on austenitic stainless steel grade 304 and martensitic stainless steel grade 410L in hot rolling. Stainless steels have traditionally been divided into categories depending on their structure at room temperature. The thickness of the oxide scale on the steels was controlled by the oxidation time. The hot rolling tests were carried out on a 2-high Hille 100 experimental rolling mill and the rolling parameters including rolling force and reduction were collected. Friction coefficients were calculated and characteristics of the oxide scale of the steels before and after hot rolling were investigated. Finite element method (FEM) has been employed in this study and the oxide scale layers and surface roughness have been considered in the FEM model. 


\section{Experimental details}

\subsection{Material and specimen geometry}

The chemical compositions of stainless steel grades 304 and 410L are shown in Table 1. The mechanical properties of the stainless steels are given in Table 2. All the materials used in the experiment were taken from hot rolled strips and the specimens were machined to the size of $100(\mathrm{~W}) \times 400(\mathrm{~L}) \times 10(\mathrm{H}) \mathrm{mm}^{3}$. In order to assist the sample to be bitten into the roll gap, the front of the specimen was tapered to a thickness of $1 \mathrm{~mm}$ and a length of $80 \mathrm{~mm}$. The surface of the specimens was ground and the measured surface roughness $R_{a}$ was $0.25 \mu \mathrm{m}$. Small samples of $15(\mathrm{~W}) \times 15(\mathrm{~L}) \times 10(\mathrm{H}) \mathrm{mm}^{3}$ were cut from the same material with the same surface roughness for the oxidation test and were placed with the rolling specimens in the electric resistance furnace to study the composition and the thickness of the oxide scale before hot rolling.

Table 1 Chemical compositions of the stainless steels (wt.\%)

\begin{tabular}{lcccccccccc}
\hline Steel grade & $\mathrm{C}$ & $\mathrm{Cr}$ & $\mathrm{Ni}$ & $\mathrm{Si}$ & $\mathrm{Mn}$ & $\mathrm{Nb}$ & $\mathrm{Mo}$ & $\mathrm{Cu}$ & $\mathrm{Co}$ & $\mathrm{Fe}$ \\
\hline 304 & 0.048 & 18.14 & 8.15 & 0.36 & 1.09 & 0.011 & 0.15 & 0.19 & 0.143 & 71.58 \\
$410 \mathrm{~L}$ & 0.0241 & 12.74 & 0.09 & 0.17 & 0.31 & 0.025 & 0.02 & 0.02 & 0.009 & 86.54 \\
\hline
\end{tabular}

Table 2 Mechanical properties of the stainless steels at room temperature

\begin{tabular}{lcccc}
\hline Steel grade & $\begin{array}{c}0.2 \% \text { proof stress } \\
(\mathrm{Mpa})\end{array}$ & $\begin{array}{c}\text { Tensile strength } \\
(\mathrm{Mpa})\end{array}$ & $\begin{array}{c}\text { Elongation } \\
(\%)\end{array}$ & $\begin{array}{c}\text { Hardness } \\
(\mathrm{HV})\end{array}$ \\
\hline 304 & 250 & 600 & 55 & 160 \\
$410 \mathrm{~L}$ & 275 & 455 & 18 & 185 \\
\hline
\end{tabular}

\subsection{Reheating and hot rolling test}

Reheating was carried out in a high temperature electric resistance furnace with a chamber size of $350(\mathrm{~W}) \times 330(\mathrm{H}) \times 870$ (D) $\mathrm{mm}^{3}$. Hot rolling experiments were carried out on a 2-high Hille 100 experimental rolling mill with rolls of $225 \mathrm{~mm}$ diameter and $254 \mathrm{~mm}$ roll body length. Rolling forces were measured by load cells on the mill. Rolling speed can be set from 0.12 to $0.72 \mathrm{~m} / \mathrm{s}$. By considering the roll speed in the real industry is far faster than that in the laboratory, in this study, the rolling speed was kept as $0.72 \mathrm{~m} / \mathrm{s}$, or $60 \mathrm{rpm}$. Reductions from $10 \%$ to $40 \%$ were selected. The samples were oxidised at $1,100^{\circ} \mathrm{C}$ for 25 and $35 \mathrm{~min}$, then rolled at $1,050^{\circ} \mathrm{C}$. All the specimens were thoroughly cleaned with acetone before heating, after rolling or reheating, all the specimens were placed immediately in a cooling box with nitrogen gas to prevent further oxidation and the specimen surfaces were covered with a small block of the stainless steel 304 to prevent the spallation of the oxide scale.

\subsection{Observation and analysis}

After the specimens were cooled to room temperature, the surface of the small and the rolled samples was covered with a mixture of epoxy resin and hardener to protect the 
oxide scale. After 24 hours the resin coagulated, and then the protected oxide scale part was sectioned along the rolling direction by a Stuers Accutom50 Cutting Machine to obtain the cross-section of the oxide scale. Finally, the oxide scale sample was cold mounted, ground and polished for metallographic examination.

The microstructures, composition and thickness of the oxide scale were examined by a JEOL JSM 6490 scanning electron microscope (SEM) equipped with an energy dispersive spectroscopy (EDS). Topographic feature of the oxide scale surface was examined using an atomic force microscope (AFM).

\section{Results and discussion}

\subsection{Oxide scale thickness before and after hot rolling}

The thicknesses of the oxide scale formed on the two stainless steels before hot rolling were measured on the cross section of SEM micrographs. Figure 1(a) shows the thickness of the oxide scale before rolling. The thickness of oxide scale on the stainless steel 304 is obviously thinner than that on the stainless steel $410 \mathrm{~L}$ at $1,100^{\circ} \mathrm{C}$ at the same oxidation time, indicating that the stainless steel 304 has higher oxidation resistance. $\mathrm{Cr}$ is the main element for high temperature corrosion resistance of stainless steels. Generally, it is considered as favourable and the higher the $\mathrm{Cr}$ concentration the higher the oxidation resistance (Young, 2008). The $\mathrm{Cr}$ content of the stainless steel 304 is $18.14 \mathrm{wt} . \%$, which is much higher than that of the stainless steel $410 \mathrm{~L}$, and then thinner oxide scale was formed during oxidation. Figure 1(b) shows the relationship between the reduction and the thickness of the oxide scale after hot rolling. It can be seen that the oxide scale thickness decreases linearly with an increase of reduction. Standard deviation of the oxide scale thickness for the measurement increases with increasing reduction, and this indicates that the uniformity of the oxide scale is affected by the increase of the reduction. The uniformity of the oxide scale is associated with the even surface and steel/oxide interface. The equations of linear fit to the measurements in Figure 1(b) are shown in Table 3. The multiple coefficient of determination $\mathrm{R}^{2}$ is a measure of the loss of predictive power or shrinkage in regression. In the equations, $x$ is the reduction in thickness, and $\mathrm{y}$ is the oxide scale thickness in $\mu \mathrm{m}$. With different thickness of the oxide scale before rolling, the slops of the linear fit lines of the stainless steel 304 are smaller than that of the stainless steel 410L. It indicates that the thinner oxide scale formed on the stainless steel 304 has higher resistance to be deformed in hot rolling. The composition and thickness of the oxide scale play roles in the deformation of oxide scale in hot rolling. Different compositions of oxide scales have different mechanical properties. On carbon steels, the oxide scale is mainly made of iron oxides. The hardness of $\mathrm{FeO}, \mathrm{Fe}_{3} \mathrm{O}_{4}$, and $\mathrm{Fe}_{2} \mathrm{O}_{3}$ are 460, 540 and 1,050 $\mathrm{HV}$, respectively at room temperature (Luong and Heijkoop, 1981). However, at $900^{\circ} \mathrm{C}$, the above values drop to 105,366 and $516 \mathrm{HV}$, respectively (Lundberg and Gustafsson, 1994). The hardness of the oxides formed on the stainless steel is affected by the alloy elements, oxidising atmosphere and time (Amano et al., 2006), and the volume ratio of iron oxides to $\mathrm{Fe}-\mathrm{Cr}$ spinel is also varied with oxidation temperature and time (Cheng et al., 2015b). 
Figure 1 Thickness of oxide scale on two stainless steels, (a) before hot rolling and (b) after hot rolling at different reductions (see online version for colours)
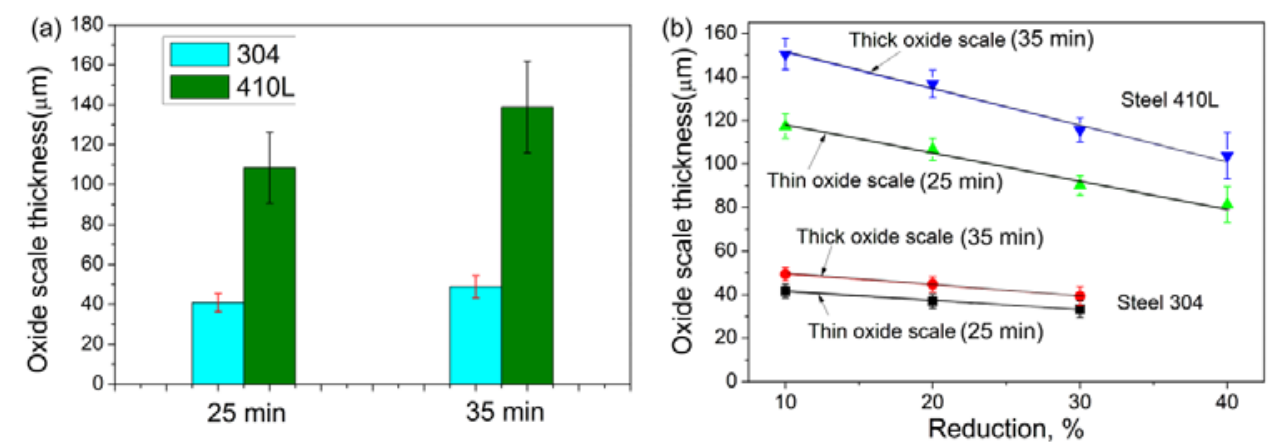

Table 3 linear fit regression equations derived from the lines in Figure 1(b)

\begin{tabular}{lccc}
\hline Steel grade & Oxidation time $(\mathrm{min})$ & Linear fit regression equation & $R^{2}$ \\
\hline 304 & 25 & $y=-41.84 x+45.62$ & 0.98 \\
& 35 & $y=-50.16 x+54.55$ & 0.99 \\
$410 \mathrm{~L}$ & 25 & $y=-129.79 x+130.89$ & 0.97 \\
& 35 & $y=-167.99 x+168.14$ & 0.96 \\
\hline
\end{tabular}

Note: $x$ is the reduction in thickness and $y$ is the oxide scale thickness in $\mu \mathrm{m}$.

\subsection{Characterisations of the oxide scale deformation}

\subsubsection{The deformation of the oxide scale on the stainless steel 304}

Figure 2 illustrates the longitudinal cross section of the oxide scale on the stainless steel 304 before and after the deformation in hot rolling. Figure 3 shows the EDS line scanning element analysis of oxide scale on the stainless steel 304 in Figures 2(a) and 2(b), which are the oxide scale formed at 25 and $35 \mathrm{~min}$ before hot rolling, respectively. The outer oxide layer is made of iron oxides and the inner oxide layer is mainly formed by $\mathrm{Fe}-\mathrm{Cr}$ spinel with a small portion of $\mathrm{Ni}$. This result agrees with the observation of Cheng et al. (2014b, 2015b). Generally, the outer oxide layer is a combination of $\mathrm{Fe}_{2} \mathrm{O}_{3}$ and $\mathrm{Fe}_{3} \mathrm{O}_{4}$ whereas, as indicated by Lee et al. (1991), the inner layer is formed by different proportion of $\mathrm{FeCr}_{2} \mathrm{O}_{4}, \mathrm{NiFe}_{2} \mathrm{O}_{4}$ and $\mathrm{Fe}_{3} \mathrm{O}_{4}$. There is a very severe spallation of the oxide scale on the stainless steel 304 during cooling off because of the large difference of the thermal conductivity between the steel substrate and the oxide scale. As seen in Figures 2(a) and 2(b), the outer layer of the oxide scale is detached from the inner layer. Figures 2(a1) to 2(b2) shows that, at the same reduction, with a thicker oxide scale formed at $35 \mathrm{~min}$, the interface of steel/oxide becomes rougher after hot rolling. The outer oxide layer is roughly $50 \%$ of the whole oxide scale, and the iron oxides are pulverised or fragmented. In the case of the oxide scale formed at $25 \mathrm{~min}$, there is not much difference of the deformed oxide scale when the reduction is from $10 \%$ to $30 \%$, and the steel/oxide interface is slightly rougher with an increase of reduction. In the case of the oxide scale formed at $35 \mathrm{~min}$, roughening of the interface between the oxide scale and the steel substrate is obvious even at the small reduction of $10 \%$. The inner spinel oxide layer is fragmented and indented into the steel substrate, and the steel substrate is 
extruded through the cracks of the inner spinel oxides, causing a very rough steel/oxide interface at the high reduction. It seems that the characterisation of oxide scale deformation in hot rolling differs as the thickness of the oxide scale differs. The thickness of $\mathrm{Fe}, \mathrm{Cr}$, Ni spinel increases with increasing oxidation time, because it is hard and brittle, resulting in fracture and displaying zig-zag feature under reduction. The deformation behaviour of the oxide scale of the stainless steel 304 is sensitive to its thickness in hot rolling.

Figure 2 SEM micrograph of the cross section of the hot-rolled specimen on the stainless steel 304 along the rolling direction (a) oxide scale formed at $25 \mathrm{~min}$ before rolling; (a1)(a2) different reduction for the oxide scale in (a); (b) oxide scale formed at 35 min before rolling; and (b1)(b2) different reduction for the oxide scale in (b) (see online version for colours)
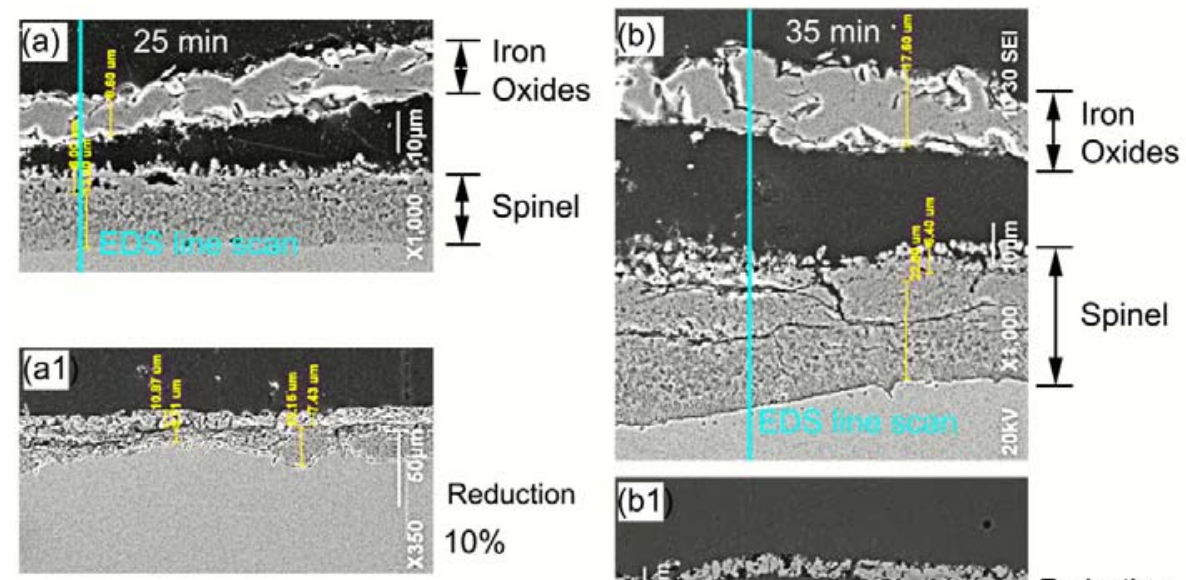

\section{Reduction $10 \%$}
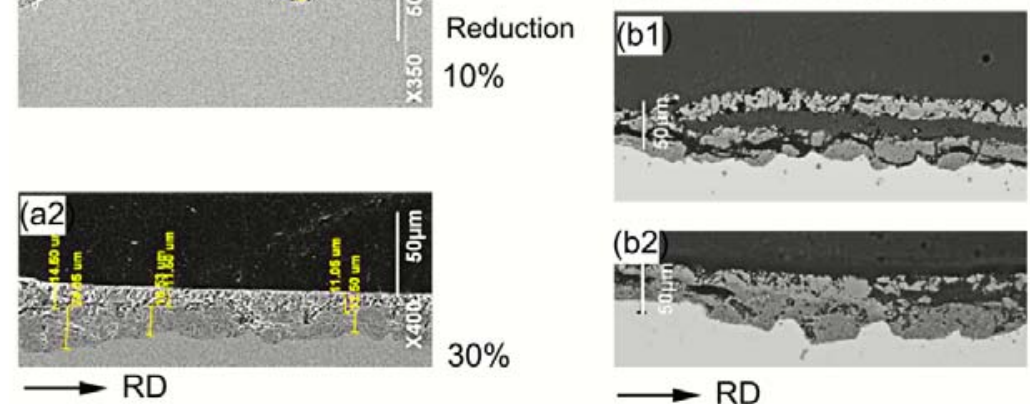

Reduction

$10 \%$

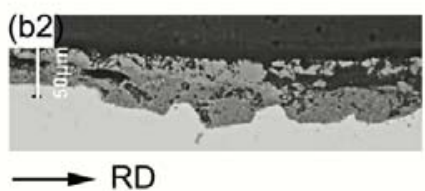

$30 \%$

$30 \%$

Figure 3 EDS line scanning element analysis of oxide scale on the stainless steel 304 in Figures 2(a) and 2(b), (a) $25 \mathrm{~min}$ and (b) $35 \mathrm{~min}$ (see online version for colours)
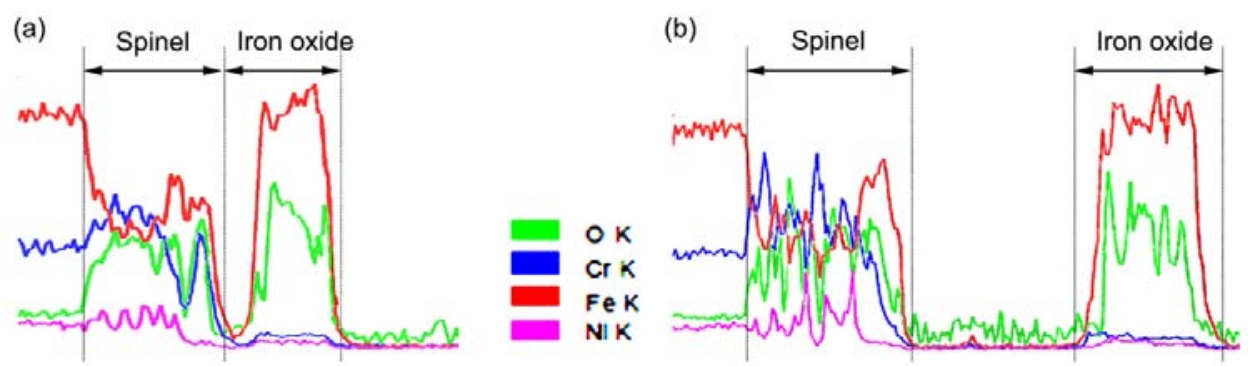
Figure 4 SEM micrograph of the cross section of the hot-rolled specimen on the stainless steel $410 \mathrm{~L}$ along the rolling redirection (a) oxide scale formed at $25 \mathrm{~min}$ before rolling; (a1)-(a3) different reduction for the oxide scale in (a); (b) oxide scale formed at $35 \mathrm{~min}$ before rolling; and (b1)-(b3) different reduction for the oxide scale in (b) (see online version for colours)
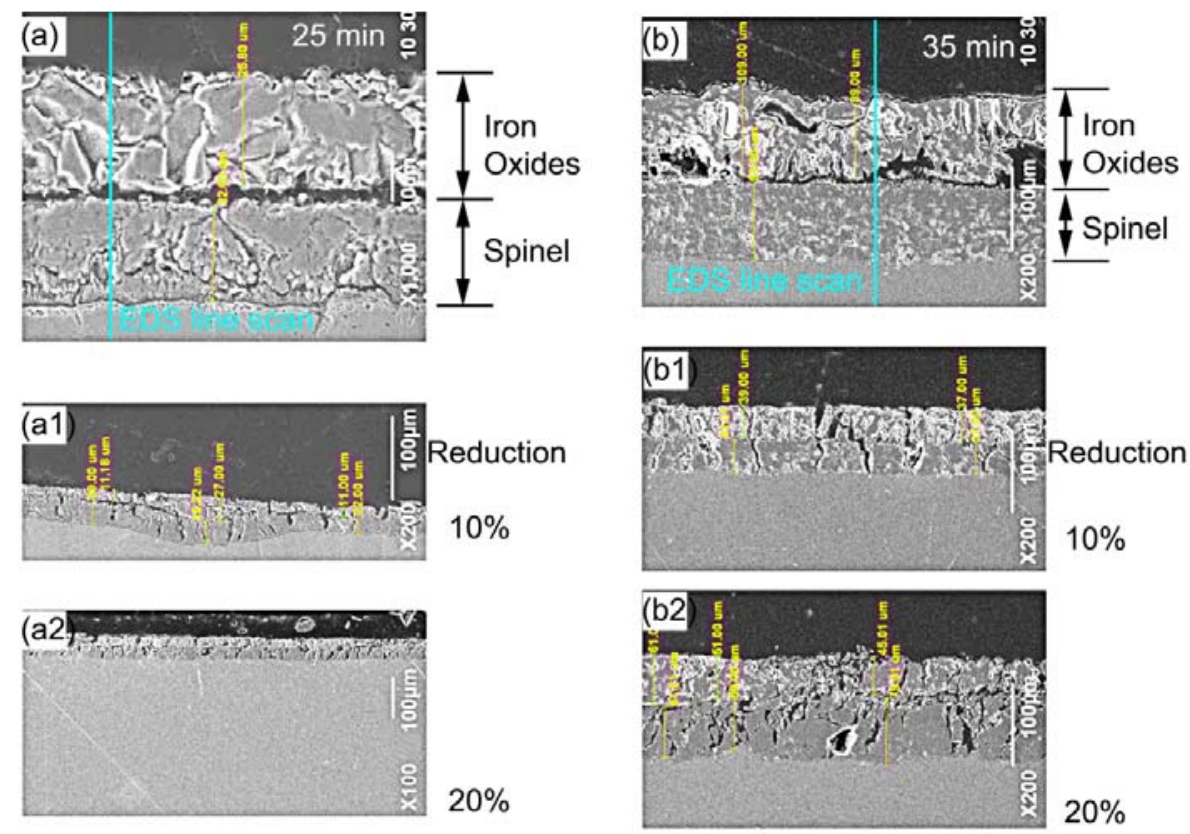

$20 \%$

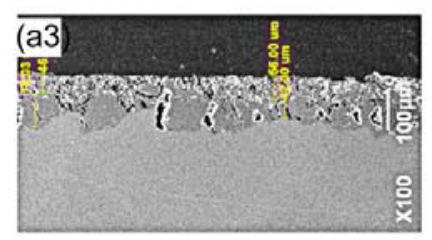

$30 \%$

RD

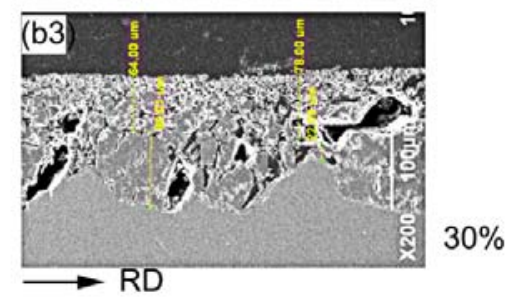

Figure 5 EDS line scanning element analysis of oxide scale on the stainless steel 410L in Figures 4(a) and 4(b), (a) $25 \mathrm{~min}$ and (b) $35 \mathrm{~min}$ (see online version for colours)

(a)

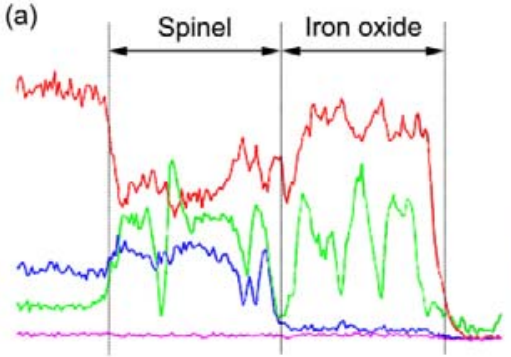

(b)

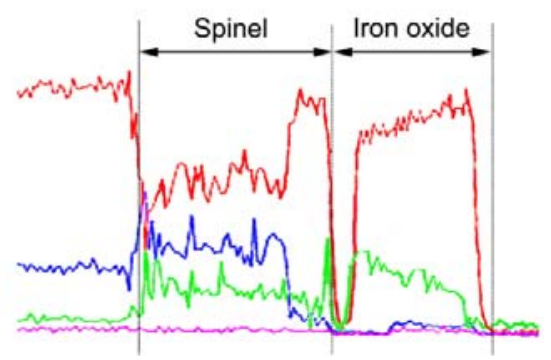




\subsubsection{The deformation of the oxide scale on the stainless steel $410 \mathrm{~L}$}

Figure 4 illustrates the longitudinal cross section of the oxide scale on the stainless steel $410 \mathrm{~L}$ before and after the deformation. Figure 5 shows the EDS line scanning element analysis of oxide scale on the stainless steel 410L in Figures 4(a) and 4(b), which are the oxide scale formed at 25 and $35 \mathrm{~min}$ before hot rolling, respectively. There are very clear two layers of the oxide scale. The outer oxide layer is made of iron oxides and the inner oxide layer is mainly $\mathrm{Fe}-\mathrm{Cr}$ spinel. The volume ratio of the outer layer to inner layer of oxide scale is roughly $1: 1$. The thickness of the oxide scale is more than double than that formed on the stainless steel 304 at the same oxidation time [Figure 1(a)]. Figures 4(a1) to 4(b2) shows that the deformation behaviour of the oxide scale is similar as the rolling reduction is from $10 \%$ to $20 \%$. The oxide scale deforms uniformly, and there is still very clear interface between the outer and the inner oxide layer. Cracks in the thickness direction were observed in the outer and the inner oxide layers respectively, indicating that the oxide scale on the stainless steel $410 \mathrm{~L}$ is still brittle. When the reduction is higher than $30 \%$, as seen in Figures 4(a3) to 4(b3), the inner Fe-Cr spinel is fragmented and indented into the steel substrate causing a rough steel/oxide interface. The outer layer of iron oxides are pulverised and covered on the top. The transition from the uniform to the non-uniform deformation of the oxide scale is associated greatly with the rolling reduction in hot rolling of the stainless steel 410L with different oxide scale thicknesses.

\subsection{Friction coefficient in hot rolling}

A formula developed by Alexander et al. (1987) on the basis of Oroman's model was used for inverse calculation of the friction coefficient. The model is based on the static equilibrium of the forces in a slab of metal undergoing plastic deformation between the rolls. This model is described in Wei et al. (2009b, 2011) and Cheng et al. (2014a).

$$
\frac{d\left(\sigma_{x} h\right)}{d x}+p \frac{d h}{d x} \mp 2 \mu p=0
$$

where $p$ is the roll pressure, $h$ is the strip thickness, $\sigma_{x}$ is the stress in the rolling direction, and $x$ is the distance in the direction of rolling. The sign of the frictional traction in equation (1) changes from being negative to positive at the neutral point (Lenard, 2007).

According to Lenard et al. (1999), the yield stress of the steel can be described as:

$$
\sigma_{\text {steel }}=\sigma_{0} \cdot e^{-a T} \cdot k_{1} \varepsilon^{m_{1}} \cdot k_{2} \dot{\varepsilon}^{m_{2}}
$$

where $\sigma_{\text {steel }}$ is the yield stress, $\sigma_{0}$ the base yield stress, $\varepsilon$ and $\dot{\varepsilon}$ the true strain and strain rate $\left(\mathrm{s}^{-1}\right)$, respectively, $T$ the temperature in $K$, and $a, k_{1}, k_{2}, m_{1}$ and $m_{2}$ are constants.

In Alexander's program, the flow stress is modified in the following form (Alexander et al., 1987).

$$
\sigma_{\text {steel }}=A \cdot(1+B \varepsilon)^{n_{1}} \cdot(1+D \dot{\varepsilon})^{n_{2}}
$$

In which $A=\sigma_{0} \cdot e^{-a T}$, where $B, D, n_{1}$ and $n_{2}$ are constants. Assuming $D=B=1,000>>1$, equation (3) still complies with equation (2). Sufficiently, $A, n_{1}$ and $n_{2}$ in equation (3) are determined by multiple-regression. 
Because the rolling speed is kept as $0.72 \mathrm{~m} / \mathrm{s}$, the strain rate is in the range $7-18 \mathrm{~s}^{-1}$ that depends on reduction in thickness according to Machida and Katsumata (1984).

$$
\overline{\dot{\varepsilon}}=\frac{2 \pi n}{60 \sqrt{r}} \cdot \sqrt{\frac{R}{H_{0}}} \cdot \ln \left(\frac{1}{1-r}\right)
$$

where $\overline{\dot{\varepsilon}}$ is the mean rolling strain rate, $n$ is the roll speed (rpm), $r$ is the rolling reduction, $R$ is the roll radius (mm), and $H_{0}$ is the thickness before reduction (mm). In the experiments, reductions of $10,20,30$ and $40 \%$ correspond to strain rates of $7,11,14$ and $18 \mathrm{~s}^{-1}$, respectively.

Figure 6 True $\sigma-\varepsilon$ curves obtained from compression tests and regression equations at $1,050^{\circ} \mathrm{C}$, (a) stainless steel 304 and (b) stainless steel 410L (see online version for colours)
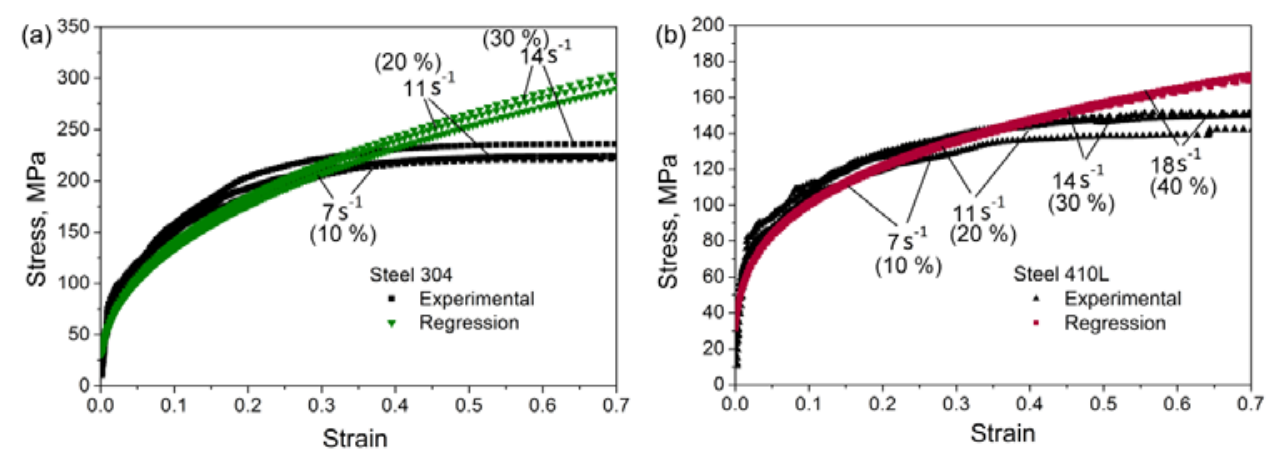

Table 4 The regression equations for true $\sigma-\varepsilon$ at different reductions at $1,050^{\circ} \mathrm{C}$

\begin{tabular}{lcc}
\hline Steel grade & Strain rate $\left(s^{-1}\right)$ & Regression equation \\
\hline 304 & 7 & $\sigma=18.25 \times(1+1,000 \varepsilon)^{0.43}$ \\
11 & $\sigma=26.40 \times(1+1,000 \varepsilon)^{0.37}$ \\
14 & $\sigma=24.75 \times(1+1,000 \varepsilon)^{0.37}$ \\
$410 \mathrm{~L}$ & 11 & $\sigma=36.62 \times(1+1,000 \varepsilon)^{0.23}$ \\
& 14 & $\sigma=27.80 \times(1+1,000 \varepsilon)^{0.27}$ \\
18 & $\sigma=31.04 \times(1+1,000 \varepsilon)^{0.26}$ \\
& & $\sigma=20.33 \times(1+1,000 \varepsilon)^{0.34}$ \\
\hline
\end{tabular}

In order to determine the flow stress model adapted by Alexander's program, compression tests were carried out for the stainless steels on Gleeble-3500 Hydro Wedge testing system at different strain rates that correspond to different reductions at $1,050^{\circ} \mathrm{C}$. The rolling strain in the experiments is related to rolling reduction. In a rolling pass, the total true strain is $\varepsilon=\ln \left(H_{0} / H\right)$, where $H_{0}$ is the strip entry thickness and $H$ is the strip exit thickness. Reduction $30 \%$ corresponds to a true strain of 0.36 and reduction $40 \%$ corresponds to a true strain of 0.51 . Figure 6 shows the experimental and the regression curves according to equation (3). It has to be noticed that, due to a small strain rate range, the curves of the two stainless steels are very close. The regression curves in Figure 6(a) are conformable to the experimental curves when the strain is less than 0.4 , which is good because the maximum reduction adopted for the steel 304 is about $30 \%$; while the regression curves in Figure 6(b) are conformable to the experimental curves when the 
strain is less than 0.55 , which is also good because the maximum reduction adopted for the steel $410 \mathrm{~L}$ is about $40 \%$. It can be seen that the flow stress of the stainless steel 304 is much higher than that of the stainless steel 410L at the strain between 0.1 and 0.4 at $1,050^{\circ} \mathrm{C}$. It can be concluded that the stainless steel $410 \mathrm{~L}$ becomes softer at $1,050^{\circ} \mathrm{C}$, although this martensitic stainless steel has a higher tensile strength at room temperature. The two stainless steel exhibits austenitic phase at this temperature. Table 4 shows the regression equations according to equation (3) based on the different strain rates.

Figure 7 The relationship between friction coefficient and reduction with different oxide scale thickness, (a) stainless steel 304 and (b) stainless steel 410L (see online version for colours)
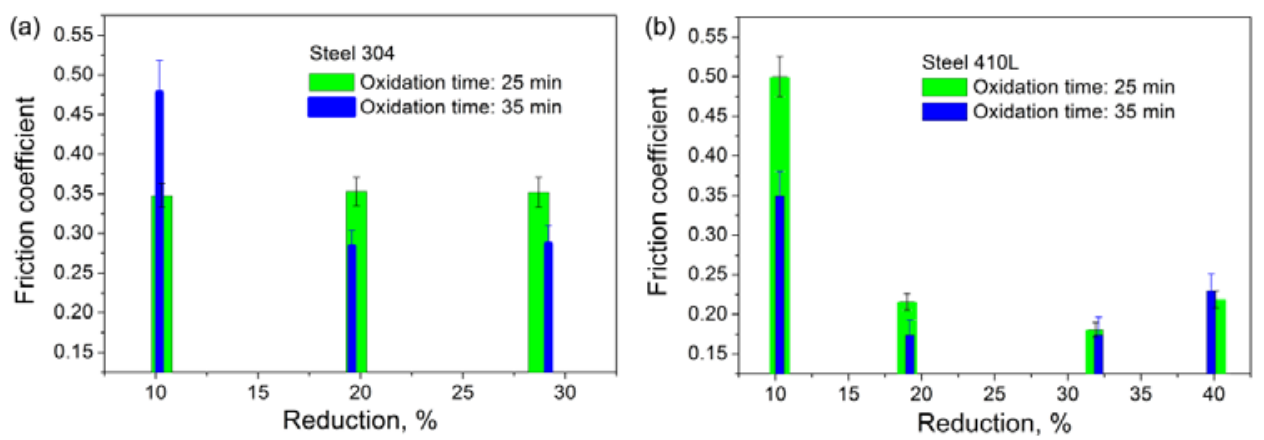

The coefficient of friction was adjusted to a number until the output separating rolling force is less than $1 \%$ error with the measured value. The relationship between the reduction and the calculated friction coefficient is shown in Figure 7. In the case of the stainless steel 304, the oxide scale is much thinner than that on the stainless steel 410L at the same oxidation time (Figure 1). At the low reduction of $10 \%$, the thicker oxide scale on the stainless steel 304 causes high friction coefficient. Wei et al. (2009b, 2011) found that the integral of the oxide scale on stainless steels was improved with increasing reduction in hot rolling. It was observed that the oxide scale on the stainless steel 304 was easily peeled off at the reduction of $10 \%$ [Figure 2(b1)]. However, as the reduction increases to $20 \%$, the thicker oxide scales on the stainless steel 304 leads to a lower friction coefficient, and this tendency takes place on the stainless steel $410 \mathrm{~L}$ as well. Munther and Lenard (1999) found that the oxide scale thickness appears to have a greater effect on friction than the oxide scale composition, and thicker oxide scales give lower friction coefficient values. The same result was also confirmed by Luong and Heijkoop (1981). Suárez et al. (2009) concluded that the deformation temperature is the important factor affecting the plastic behaviour of the oxide scale formed on ultra-low carbon steel. However, the oxide scale on stainless steels may display different deformation behaviour from that on carbon steels due to their complex oxidation behaviour (Cheng et al., 2015a). Compared to the stainless steel 304, friction coefficients of the stainless steel $410 \mathrm{~L}$ are lower than that of the stainless steel 304 at the similar reductions $(>20 \%)$, this is attributed to its thicker oxide scale and the softer steel substrate at $1,050^{\circ} \mathrm{C}$ (Figure 6). For the stainless steel 304, the deformed thicker oxide scale formed at $35 \mathrm{~min}$ displayed rougher steel/oxide interface as the reduction increases $(>20 \%)$ [Figures 2(b1) and 2(b2)], however, it has little effect on friction coefficients. Cheng et al. (2015a) found that the outer layer of oxide scale constituted with $\mathrm{Fe}_{2} \mathrm{O}_{3}$ and $\mathrm{Fe}_{3} \mathrm{O}_{4}$ 
would be fragmented and covered the rolled specimen uniformly, in this way, the bare steel substrate to contact against the roll surface will be eliminated.

An increase in the friction coefficient after increasing reduction from $32 \%$ to $40 \%$ is shown in Figure 7(b). The thicker oxide scale on the steel 410L has not caused a decrease in friction coefficient at the reduction of $40 \%$ compared to that at lower reductions. On the steel $410 \mathrm{~L}$, the non-uniform deformation of the oxide scale is associated greatly with the rolling reduction but not the thickness, therefore, at this reduction, the inner $\mathrm{Fe}-\mathrm{Cr}$ spinel is fragmented heavily and the cracks are enlarged, and this causes the steel substrate extruding from the cracks and some soft substrate might touch the roll surface, and the sticking occurs. As a result, friction coefficient increases. This phenomenon is different from the carbon steels, on which the porous $\mathrm{FeO}$ has a good ductility and acts as a lubricant to reduce the friction coefficient at high reductions (Krzyzanowski et al., 2010; Hidaka et al., 2003).

\subsection{Finite element analysis of surface roughness transformation}

FEM used in this study was to analysis transformation of the surface roughness of the oxide scale and the steel (steel/oxide interface) in hot rolling.

Surface roughness plays an important role because it directly affects the friction in the roll bite so that parameters such as the rolling force, torque and energy consumption are altered. With the surface roughness included in the model of strip rolling process, the oxide scale layer on the strip can be described in realistic detail, so the roughness transformation of the scale and steel during rolling can be better understood.

\subsubsection{Generation of $3 D$ rough surface profile}

The surface topography of the oxidised surface on the stainless steel before hot rolling was scanned by AFM as shown in Figure 8. It is similar to the surface profile of oxidised carbon steel (Sun et al., 2004b). This is because the top oxide on the outer layer of oxide scale on stainless steels is also $\mathrm{Fe}_{2} \mathrm{O}_{3}$ (Cheng et al., 2015b). It can be seen that the surface valleys are in a random pattern.

The surface roughness topography is assumed as a linear superposition of a series of normal distribution functions. The model has been described in the work of Jiang et al. (2006). Then, the profiles of a roughness asperity can be described as follows:

$$
z=A e^{-\left(\frac{(x-\mu)^{2}}{\sigma_{x}^{2}}+\frac{(y-v)^{2}}{\sigma_{y}^{2}}\right)}
$$

where $Z$ and $A$ are the height and the peak height of the roughness asperity respectively; $\mu$ and $v$ are the summit coordinates; $\sigma_{x}$ and $\sigma_{y}$ are standard deviations that reflect the wave length or sharpness of the normal distribution function.

For any plane $p$ parallel to $Z$ as described by:

$$
p: A x+B y+C=0
$$

intersects the surface described by equation (4), the curve at the intersection can be obtained by eliminating $y$ (or $x$ ) in equation (5) using equation 6), as shown in equation (7). 


$$
z=A^{\prime} e^{\frac{-\left(x-\mu^{\prime}\right)^{2}}{2 \sigma^{2}}}
$$

where $A^{\prime}$ is the modified peak height of the roughness asperity and $\mu^{\prime}$ is the modified summit $x$ coordinates. The intersection curve is shown in equation (7). It can be seen that the curve at the intersection still has a Gaussian function form. If the asperities of the rough surface are constituted by a series of profiles expressed by equation (4), any profile of a surface section can be constituted by a series of curves expressed by equation (4). The profile of a single asperity can be described by the Gaussian function in $3 \mathrm{D}$ or $2 \mathrm{D}$ form. Gaussian function is asymmetrical at its peak position. As $x-\mu^{\prime}=3 \sigma$ or $x-\mu^{\prime}=-3 \sigma, z$ is very close to zero in equation (6) compared with the peak value of $z$ (Jiang et al., 2010).

Figure 8 Oxidised stainless steel surface profile scanned by AFM (see online version for colours)

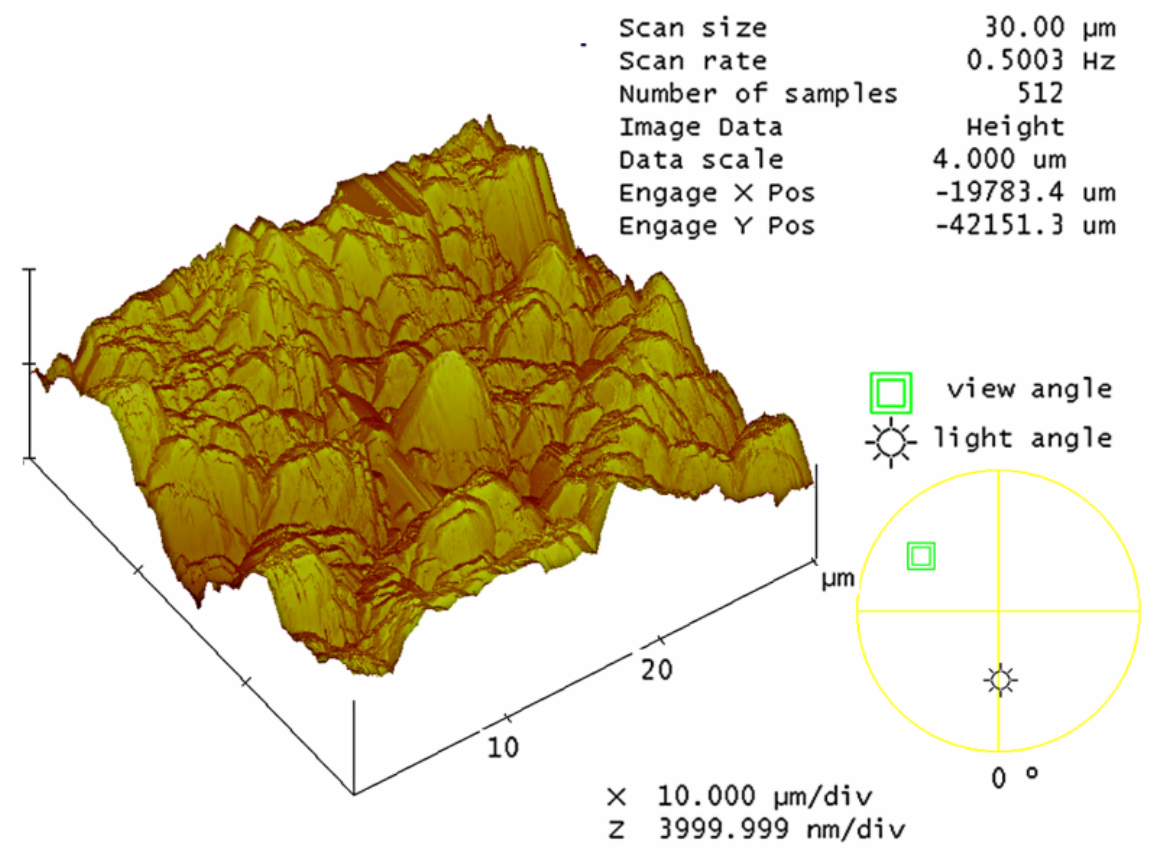

For a rough surface, the peak height $A$ of an asperity is a random number and usually obeys normal distribution. The distribution of wavelength $\lambda_{x}, \lambda_{y}$ of the asperities of the oxide scale has a single peak in the range of 20-30 $\mu \mathrm{m} . A, \lambda_{x}$ and $\lambda_{y}$, the parameters of a roughness asperity profile are assumed to have a normal distribution in a specified rough surface. When the mean value $A_{m}, \lambda_{x m}, \lambda_{y m}$ and the standard deviation value $\sigma_{a}, \sigma_{x}, \sigma_{y}$ of $A$, $\lambda_{x}, \lambda_{y}$ are specified, the parameters of a roughness asperity profile $A, \lambda_{x}, \lambda_{y}$ in a small rectangular area can be obtained by running a random number generator which uses normal distribution functions $N\left(A_{m}, \sigma_{a}\right), N\left(\lambda_{x m}, \sigma_{x}\right)$ and $N\left(\lambda_{y m}, \sigma_{y}\right)$, respectively.

Figures 9 (a) to 9 (b) show the rough surface generated by the model stated in equation (5) in a rectangular area. The peak distribution and profile in Figure 9(b) and Figure 8 are relatively close, which shows that the surface roughness generated is similar to a real one if suitable parameters are used. 
Figure 9 (a) Generated individual 3D valley and (b) Generated 3D surface profile for simulation (see online version for colours)
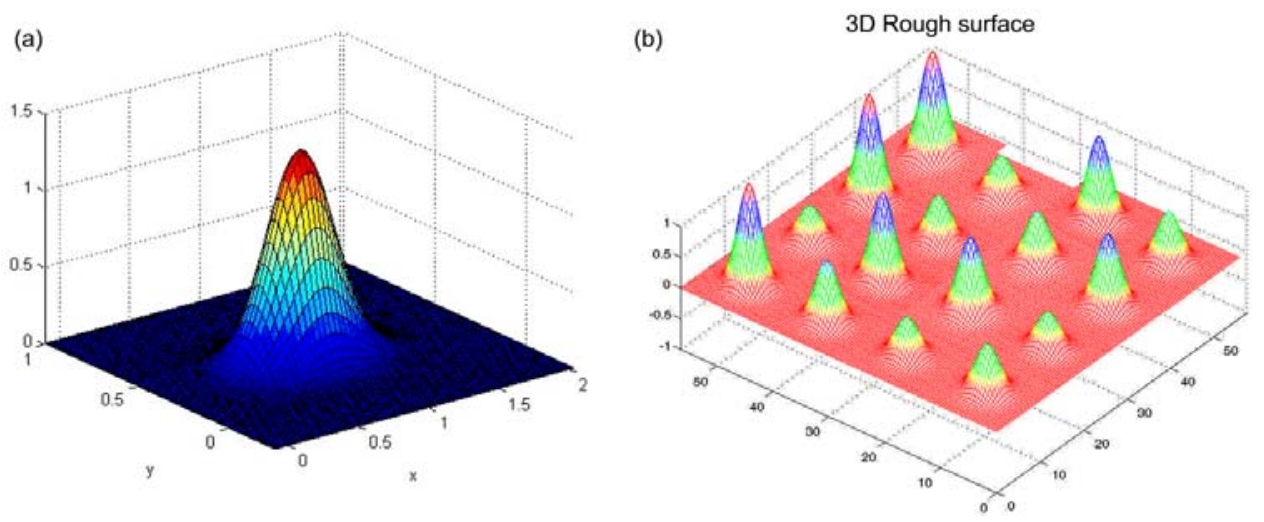

\subsubsection{Finite element model}

According to the experimental results, two oxide scale layers are considered. The outer layer of the oxide scale is iron oxides and the inner layer of the oxide scale is chromite. Echsler et al. (2003) found that the flow stress-strain curve of oxide scale was similar to that of the substrate steel in a bending experiment of mild steel. The flow stress of the scale layer is always less than that of the steel substrate for the same strain. The empirical formula obtained by Yu and Lenard (2002) estimated the average flow stress of the scale layer is 123.37 to $443.1 \mathrm{MPa}$, which may be larger than that of the steel substrate.

In this simulation, the oxide scale is assumed to be elastic-plastic materials and the flow stress is assumed to be proportional to that of steel substrate and can be expressed by the form of equation (8).

$$
\sigma=k \cdot \sigma_{\text {steel }}
$$

where $k$ is the proportional constant, and is derived from $\sigma_{\text {steel }}$ equation (3).

The Poisson ratio is 0.3 and Young's modulus of whole oxide scale is calculated by using equation (9) (Morrel, 1987). $E_{0}=220$ and $280 \mathrm{GN} / \mathrm{m}^{2}$ for iron oxide and chromite, respectively (Krzyzanowski et al., 2010).

$$
E=E_{0}\left[1-4.7 \times 10^{-4}(T-25)\right] \mathrm{GPa}
$$

Coulomb's friction model was used in this study. As the friction coefficient is affected by the thickness of oxide scale, temperature, speed, pressure, reduction, and lubrication, it varies in different experiments and may change during rolling. The friction coefficient was assumed a constant in each case in the simulation. The friction coefficient used in the simulation was assumed as a constant and used the value from the inverse calculation as shown in Figure 7.

A series of simulations having the same rolling and profile parameter were performed. $k$ varies from 0.5 to 1.2 based on the results of Echsler et al. (2003) and $\mathrm{Yu}$ and Lenard (2002). Figure 10 shows the surface roughness of the oxide scales and steel after deformation. It can be seen that the surface roughness of both the oxide scale 
and the steel substrate keep stable when the constant $k$ is larger than 1.0. $k$ is assumed to be 1.2 in the simulation.

Figure 10 Effect of $k$ values on surface roughness of oxide scale and steel (see online version for colours)

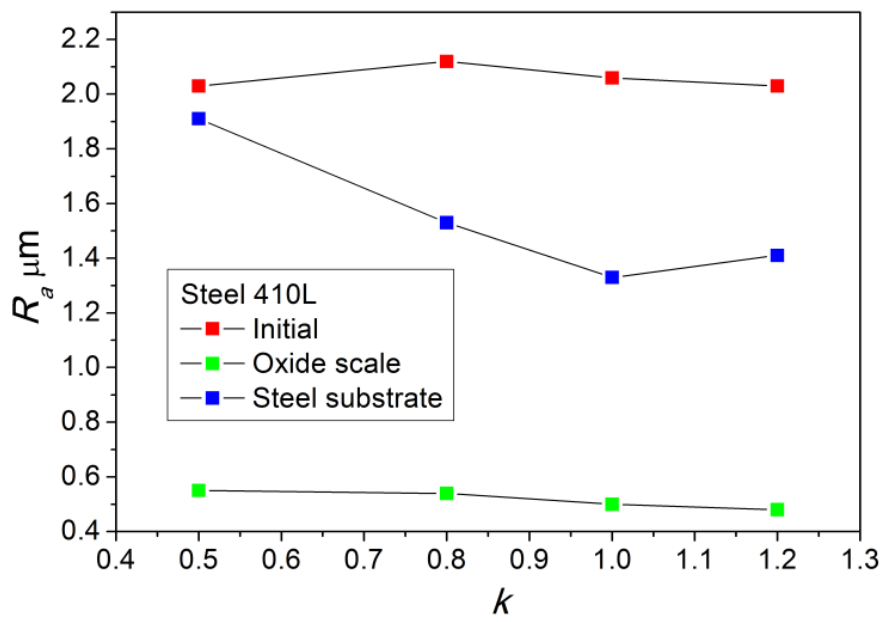

\subsubsection{Simulation results and discussion}

\subsubsection{Effect of reduction}

The rolling parameters used in the simulation for the effect of rolling reduction are adopted as those in the experiment. The steel grade $410 \mathrm{~L}$ was chosen for simulation firstly. The oxide scale thickness is $140 \mu \mathrm{m}$, corresponding to the oxide scale formed for 35 min [Figure 4(b)]. It is assumed that the thickness of iron oxide is one order of magnitude of the thickness of chrome oxide, i.e., the thickness of iron oxide and spinel chromite oxide are $70 \mu \mathrm{m}$ equally.

Figure 11 Effect of reduction on surface roughness of oxide scale and steel, (a) stainless steel $410 \mathrm{~L}$ and (b) stainless steel 304 (see online version for colours)
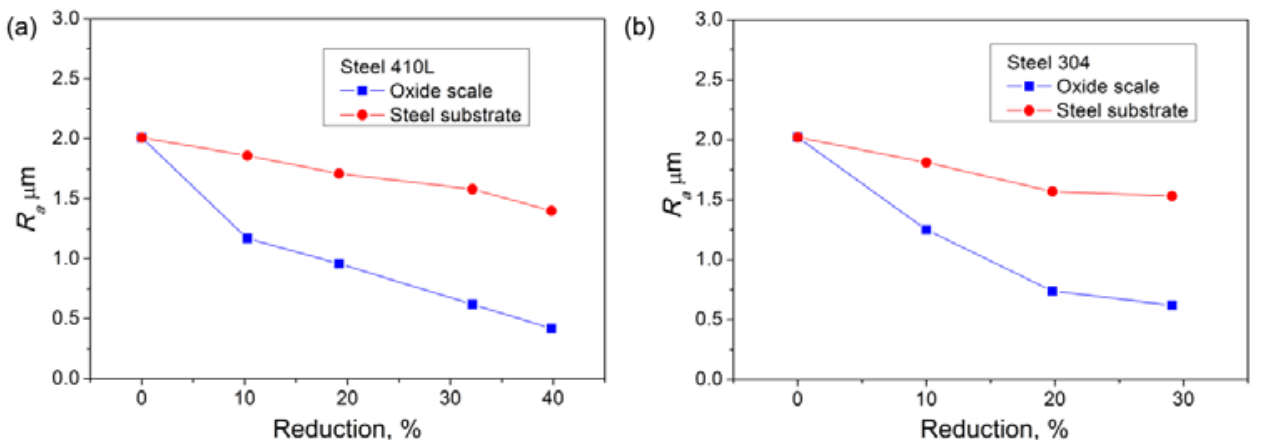
Effect of reduction on surface roughness of the stainless steel 410L is shown in Figure 11(a). The surface roughness decreases with an increase of reduction and the decrease of scale surface roughness is more than that of steel substrate, which is accordance with the experimental results. When the reduction is higher than $20 \%$, the tendency for decreasing surface roughness is not so significant. In fact, the peaks of surface asperities encounter the roll, and they are compressed firstly. This causes the peaks of the asperities to be flattened quickly and then the surface roughness decreases dramatically. The contact area between the oxide scale and the roll increases when more and more peaks of the asperities are flattened. Simulation was also carried out for the stainless steel 304, as shown in Figure 11(b) and the result is similar to that of the stainless steel $410 \mathrm{~L}$.

\subsubsection{Effect of initial surface roughness}

The initial surface influences the lubrication in sheet forming of stainless steel (Nilsson et al., 2010). Initial surface roughness chosen is in the range of 2.1 to $4.0 \mu \mathrm{m}$ based on experimental results after descaling but before rolling (Sun et al., 2004a). The steel grade 410L was chosen for simulation firstly. The oxide scale thickness is $140 \mu \mathrm{m}$.

The simulation results of the stainless steel 410L are shown in Figure 12(a). Two reductions were used. It can be seen that the final surface roughness of both the oxide scale and the steel substrate increases linearly with an increase of initial surface roughness. At the higher reduction of $40 \%$, the slopes of the lines are smaller than those at the lower reduction; this means that the initial roughness influences the final surface roughness less when the reduction is high. Simulation was also carried out for the stainless steel 304 with oxide scale thickness of $70 \mu \mathrm{m}$, as shown in Figure 12(b) and the result shows the similar trend as that of the stainless steel 410L.

Figure 12 Final surface roughness of oxide scale and steel vs. initial surface roughness,

(a) stainless steel 410L and (b) stainless steel 304 (see online version for colours)
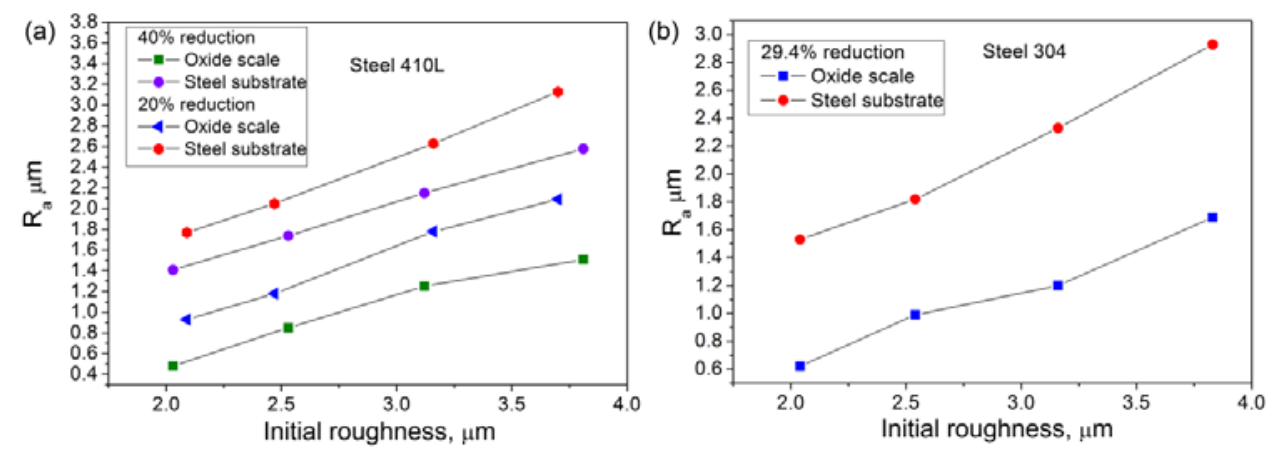

\subsubsection{Effect of oxide scale layer thickness}

Simulations with various thicknesses of the oxide scale were chosen to evaluate the effect of initial thickness of the oxide scale on final surface roughness. The steel grade 410L was chosen for simulation firstly. Rolling reduction is $40 \%$, average asperity wavelength is $40 \mu \mathrm{m}$ and initial surface roughness is about $2.0 \mu \mathrm{m}$. 
The results of the stainless steel 410L are shown in Figure 13(a). There is not much variation of the final surface roughness with increasing oxide scale thickness. As the oxide scale thickness increases from 100 to $160 \mu \mathrm{m}$, the steel surface roughness increases slightly. The result is different from of the oxide scale on carbon steel (Jiang et al., 2010), in which the increase of final surface roughness of steel substrate is faster than that of oxide scale. However, the simulation for the surface roughness transformation of carbon steel was only considered one layer of oxide scale and the $\mathrm{FeO}$ is the main constituent. Simulation was also carried out for the stainless steel 304, as shown in Figure 13(b) and the result is similar to that of the stainless steel 410L.

Figure 13 Final surface roughness of oxide scale and steel vs. oxide scale thickness, (a) stainless steel 410L and (b) stainless steel 304 (see online version for colours)
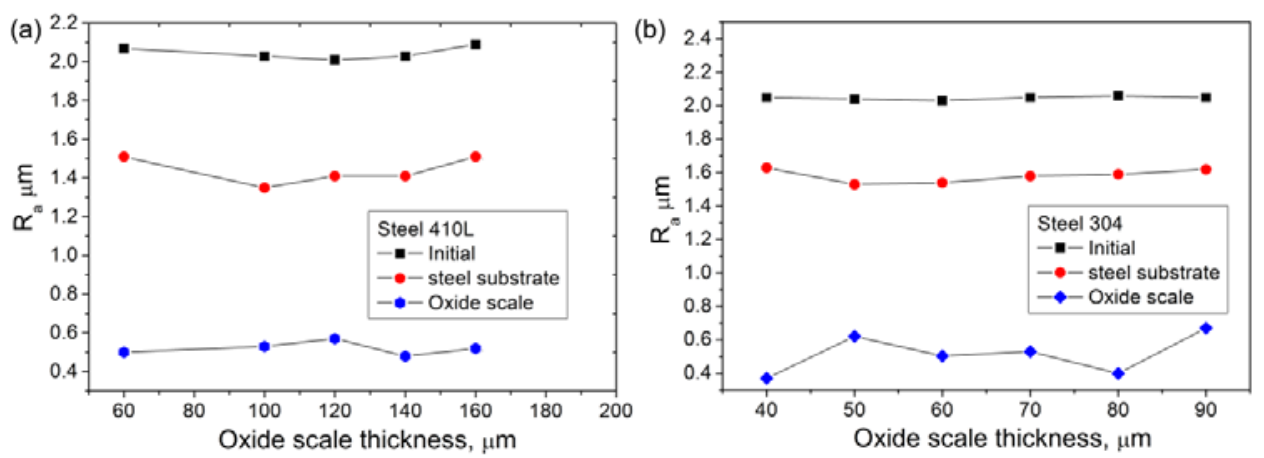

\subsubsection{Comparison of simulation results with experimental results}

The values of $\mathrm{R}_{\mathrm{a}}$ of oxide scale after rolling obtained from the simulation and the experiments are compared in Figure 14(a) for the stainless steel 304 and Figure 14(b) for the stainless steel $410 \mathrm{~L}$, respectively.

Figure 14 Comparison of experimental and simulation results of surface roughness vs. reduction, (a) stainless steel 304 and (b) stainless steel 410L (see online version for colours)
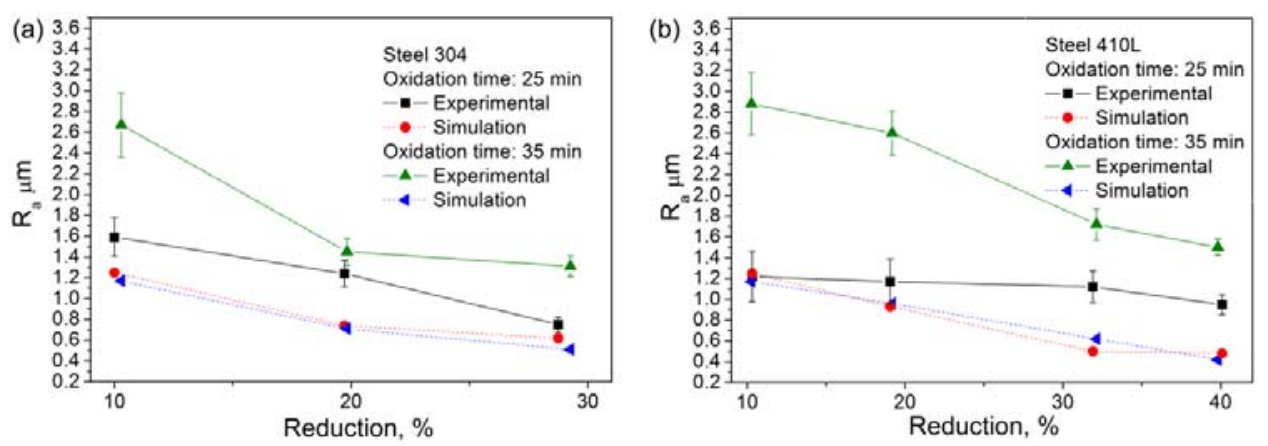

For the two stainless steels, the thicker oxide scale oxidised for 35 min has higher $\mathrm{R}_{\mathrm{a}}$ than the thinner oxide scale oxidised for $25 \mathrm{~min}$ at the same reduction, and $\mathrm{R}_{\mathrm{a}}$ decreases with an increase of reduction. However, the change of $R_{a}$ in simulation is negligible when the oxide scale thickness is different. The decreasing tendency of $R_{a}$ with increasing 
reduction is similar to that in the experiments. It is noted that the values of $R_{a}$ obtained from simulation are lower than those from experiments. The reason may be lack of compact ability of the thicker oxide scale and this may cause more broken surfaces, hence increase surface roughness. The spallation of the oxide scale on the austenitic stainless steel 304 is severe when the rolling reduction is small during cooling process, which could also increase the surface roughness.

Generally, the simulation results can match the results obtained in the experiments. The two layers of the oxide scale were employed in the simulation and the mechanical properties of the oxide layers are used same values without considering oxide compositions, therefore the simulation results of $410 \mathrm{~L}$ and the stainless steel 304 are similar. The measurement of the mechanical properties of oxide scale, which requires a combination of experiments under appropriate operating conditions and computer-based modelling (Echsler et al., 2003; Tiley et al., 1999) is a challenge. Especially, the measurement at high temperature is quite difficult. Different methodology has been employed to observe and to measure the mechanical properties of the oxide scale at high temperature. Echsler et al. (2003) found that the flow stress-strain curve of oxide scale was similar to that of the substrate steel in a bending experiment of mild steel. The flow stress of the scale layer is always less than that of the steel substrate for the same strain. Krzyzanowski and Beynon (1999, 2006) have investigated the failure of oxide scales formed on mild steel using high temperature tensile tests because of a longitudinal tensile stress in the stock surface ahead of contact with the roll. The oxide scale can have through-thickness cracks or delamination (Krzyzanowski et al., 2010, Krzyzanowski and Beynon, 1999). The simulation will be further considered with the composition of the oxide scale and its mechanical properties at high temperature. The developed FE simulation can be applied in the analysis of deformation behaviour of oxide scale, friction and surface roughness transfer during hot rolling of stainless steels.

\section{Conclusions}

In this paper, hot rolling tests were carried out on a 2-high Hille 100 mill. Friction coefficient was calculated and the deformation behaviour of the oxide scale on austenitic stainless steel 304 and martensitic stainless steel 410L were analysed.

Austenitic stainless steel 304 has higher oxidation resistance than martensitic stainless steel $410 \mathrm{~L}$ at $1,050^{\circ} \mathrm{C}$. The thickness of the oxide scale formed on the stainless steel 304 is more than double of that on the stainless steel $410 \mathrm{~L}$ at the same oxidation time. On the stainless steel 304 , the oxide scale exhibits higher resistance to be deformed in hot rolling and the deformation behaviour of the oxide scale is sensitive to its thickness. On the stainless steel $410 \mathrm{~L}$, the reduction in thickness is important to the uniformity of the deformed oxide scale. Friction coefficient of the steel $410 \mathrm{~L}$ is less than that of the stainless steel 304 when the reduction is higher than $20 \%$ at the rolling temperature of $1,050^{\circ} \mathrm{C}$ in the experiment.

The surface roughness transformation including the oxide scale and the steel (steel/oxide interface) of the stainless steels in hot rolling has been analysed using a FEM. 3D surface profile by generating the rough oxidised surface on stainless steel has been successfully applied for the simulation. Simulation results show that the final surface roughness decreases with increasing reduction, and the surface roughness of steel 
is always larger than that of oxide scale. Higher initial surface roughness causes higher final surface roughness.

\section{References}

Alexander, J.M., Brewer, R.C. and Rowe, G.W. (1987) Manufacturing Technology, Halsted Press, New York.

Amano, T., Okazaki, M., Takezawa, Y. and Shiino, A. (2006) 'Hardness of oxide scales on Fe-Si alloys at room- and high-temperatures', Mater. Sci. Forum, Vols. 522-523, pp.469-476.

Baddoo, N.R. (2008) 'Stainless steel in construction: a review of research, applications, challenges and opportunities', J. Constr. Steel Res., Vol. 64, pp.1199-1206.

Chang, Y-N., Lin, S-N., Liou, H-Y., Chang, C-W., Wu, C-C. and Wang, Y-C. (2013) 'Improving the surface roughness of pickled steel strip by control of rolling temperature', J. of Materi. Eng. and Perform., Vol. 22, No. 1, pp.322-329.

Cheng, X., Jiang, Z. and Wei, D. (2014a) 'Effects of oxide scale on hot rolling of an austenitic stainless steel', Int. J. Surface Science and Engineering, Vol. 8, Nos. 2-3, pp.173-187.

Cheng, X., Jiang, Z., Wei, D., Zhao, J., Monaghan, B.J., Longbottom, R.J. and Jiang, L. (2014b) 'Characteristics of oxide scale formed on ferritic stainless steels in simulated reheating atmosphere', Surf. Coat. Technol., Vol. 258, pp.257-267.

Cheng, X., Jiang, Z., Wei, D., Hao, L., Zhao, J. and Jiang, L. (2015a) 'Oxide scale characterization of ferritic stainless steel and its deformation and friction in hot rolling', Tribol. Int., Vol. 84, pp.61-70.

Cheng, X., Jiang, Z., Wei, D., Zhao, J., Monaghan, B.J., Longbottom, R.J. and Jiang, L. (2015b) 'High temperature oxidation behaviour of ferritic stainless steel SUS 430 in humid air', Met. Mater. Int., Vol. 21, No. 2, pp.251-259.

Cheng, X., Jiang, Z., Zhao, J., Wei, D., Hao, L., Peng, J., Luo, M., Ma, L., Luo, S. and Jiang, L. (2015c) 'Investigation of oxide scale on ferritic stainless steel B445J1M and its tribological effect in hot rolling', Wear, Vols. 338-339, pp.178-188.

Echsler, H., Ito, S. and Schutze, M. (2003) 'Mechanical properties of oxide scales on mild steel at 800 to $1,000^{\circ} \mathrm{C}^{\prime}$, Oxid. Met., Vol. 60, Nos. 3/4, pp.241-269.

Hidaka, Y., Anraku, T. and Ohtsuka, N. (2006) 'Deformation and fracture behavior of surface oxide scale on $\mathrm{Fe}-13 \mathrm{Cr}$ alloy in hot-rolling process', Mater. Sci. Forum, Vols. 522-523, pp.461-468.

Hidaka, Y., Anraku, T. and Otsuka, N. (2003) 'Deformation of iron oxides upon tensile tests at $600-1,250^{\circ} \mathrm{C}^{\prime}$, Oxid. Met., Vol. 59, Nos. 1-2, pp.97-113.

Jiang, Z.Y., Tang, J., Sun, W., Tieu, A.K. and Wei, D. (2010) 'Analysis of tribological feature of the oxide scale in hot strip rolling', Tribol. Int., Vol. 43, No. 8, pp.1339-1345.

Jiang, Z.Y., Tang, J., Tieu, A.K., Sun, W. and Wei, D. (2008) 'Surface roughness micro-deformation and transfer of bulk steel in hot rolling', Int. J. Surface Science and Engineering, Vol. 2, Nos. 1/2, pp.139-151.

Jiang, Z.Y., Tieu, A.K., Sun, W.H., Tang, J.N. and Wei, D.B. (2006) 'Characterisation of thin oxide scale and its surface roughness in hot metal rolling', Mater. Sci. Eng. A, Vols. 435-436, pp.434-438.

Kaladhar, M., Subbaiah, K.V. and Rao, C.H.S. (2012) 'Machining of austenitic stainless steels - a review', Int. J. of Machining and Machinability of Materials, Vol. 12, Nos. 1/2, pp.178-192.

Krzyzanowski, M. and Beynon, J.H. (1999) 'The tensile failure of mild steel oxide under hot rolling conditions', Steel Res. Int., Vol. 70, No. 1, pp.22-27.

Krzyzanowski, M. and Beynon, J.H. (2006) 'Modelling the behaviour of oxide scale in hot rolling', ISIJ Int., Vol. 46, No. 11, pp.1533-1547. 
Krzyzanowski, M., Beynon, J.H. and Farrugia, D.C.J. (2010) Oxide Scale Behavior in High Temperature Metal Processing, Wiley, Hoboken.

Lee, Y.D., Lee, Y.H., Lee, J.S. and Kim, J.K. (1991) 'Descaling behavior of types 304 and 430 annealed strips', ISIJ Int., Vol. 2, pp.952-958.

Lenard, J.G. (2007) Primer on Flat Rolling, 1st ed., Elsevier, Great Britain.

Lenard, J.G., Pietrzyk, M. and Cser, L. (1999) Mathematical and Physical Simulation of the Properties of Hot Rolled Product, Elsevier, Oxford.

Lundberg, S-E. and Gustafsson, T. (1994) 'The influence of rolling temperature on roll wear, investigated in a new high temperature test rig', J. Mater. Process Tech., Vol. 42, No. 3, pp.239-291.

Luong, L.H.S. and Heijkoop, T. (1981) 'The influence of scale on friction in hot metal working', Wear, Vol. 71, No. 1, pp.93-102.

Machida, M. and Katsumata, M. (1984) 'Effect of rolling strain rate on the grain size of austenite recrystallized immediately after hot rolling', Tetsu-to-Hagane, Vol. 70, No. 15, pp.2104-2111.

McGuire, M.F. (2008) Stainless Steel for Design Engineers, ASM International, Materials Park, $\mathrm{OH}, \mathrm{USA}$.

Morrel, R. (1987) Handbook of Properties of Technical \& Engineering Ceramics, HMSO, London.

Munther, P.A. and Lenard, J.G. (1999) 'The effect of scaling on interfacial friction in hot rolling of steels', J. Mater. Process Tech., Vol. 88, Nos. 1-3, pp.105-113.

Nilsson, M.S., Olsson, D.D., Petrushina, I., Andreasen, J.L., Bay, N., Christensen, E. and Bjerrum, N.J. (2010) 'Strategic surface topographies for enhanced lubrication in sheet forming of stainless steel', Int. J. Surface Science and Engineering, Vol. 4, No. 1, pp.68-79.

Reichardt, M. (2001) 'Surface oxide formation and acid-descaling for stainless steel', Wire Ind., Vol. 68, No. 813, pp.503, 505-507.

Suárez, L., Houbaert, Y., Eynde, X.V. and Colás, R. (2009) 'High temperature deformation of oxide scale', Corros. Sci., Vol. 51, No. 2, pp.309-315.

Sun, W., Tieu, A.K., Jiang, Z. and Lu, C. (2004a) 'High temperature oxide scale characteristics of low carbon steel in hot rolling', J. Mater. Process Tech., Vols. 155-156, pp.1307-1312.

Sun, W., Tieu, A.K., Jiang, Z., Zhu, H. and Lu, C. (2004b) 'Oxide scales growth of low-carbon steel at high temperatures', J. Mater. Process Tech., Vols. 155-156, pp.1300-1306.

Tieu, A.K., Tang, J., Jiang, Z., Sun, W. and Lu, C. (2007) 'Surface roughness transformation and deformation of the scale in hot rolling', Int. J. Surface Science and Engineering, Vol. 1, No. 1, pp.125-143.

Tiley, J., Zhang, Y. and Lenard, J.G. (1999) 'Hot compression testing of mild steel industrial reheat furnace scale', Steel Res. Int., Vol. 70, No. 11, pp.437-440.

Utsunomiya, H., Hara, K., Matsumoto, R. and Azushima, A. (2014) 'Formation mechanism of surface scale defects in hot rolling process', CIRP Ann.-Manuf. Techn., Vol. 63, No. 1, pp.261-264.

Vignal, V., Bissey-Breton, S. and Coudert, J-B. (2014) 'Mechanical properties and corrosion behaviour of low carbon martensitic stainless steel after machining', Int. J. of Machining and Machinability of Materials, Vol. 15, Nos. 1/2, pp.36-53.

Wei, D.B., Huang, J.X., Zhang, A.W., Jiang, Z.Y., Tieu, A.K., Shi, X. and Jiao, S.H. (2009a) 'Deformation of oxide scale and surface roughness transfer during hot rolling of stainless steel 304L', Int. J. Surface Science and Engineering, Vol. 3, Nos. 5-6, pp.459-470.

Wei, D.B., Huang, J.X., Zhang, A.W., Jiang, Z.Y., Tieu, A.K., Shi, X., Jiao, S.H. and Qu, X.Y. (2009b) 'Study on the oxidation of stainless steels 304 and 304L in humid air and the friction during hot rolling', Wear, Vol. 267, No. 9, pp.1741-1745.

Wei, D.B., Huang, J.X., Zhang, A.W., Jiang, Z.Y., Tieu, A.K., Shi, X. and Jiao, S.H. (2011) 'The effect of oxide scale of stainless steels on friction and surface roughness in hot rolling', Wear, Vol. 271, Nos. 9-10, pp.2417-2425. 
Young, D.J. (2008) High Temperature Oxidation and Corrosion of Metals, Elsevier, Oxford.

$\mathrm{Yu}$, Y. and Lenard, J.G. (2002) 'Estimating the resistance to deformation of the layer of scale during hot rolling of carbon steel strips', J. Mater. Process Tech., Vol. 121, No. 1, pp.60-68.

Zhang, Q., Jiang, Z. and Wei, D. (2012) 'Adhesion at oxide layer/substrate interface during sliding wear', Int. J. Surface Science and Engineering, Vol. 6, No. 4, pp.270-295.

Zhang, X., Liu, Z., Jiao, S. and Wang, G. (2009) 'Oxide scale behaviour and surface roughness under hot rolling conditions of Fe-Ni36 Invar alloy', Int. J. Surface Science and Engineering, Vol. 3, Nos. 5/6, pp.471-481. 